\title{
Policy Choices in Assembly versus Representative Democracy: Evidence from Swiss Communes
}

\author{
Patricia Funk \\ Stephan Litschig
}

September 2017

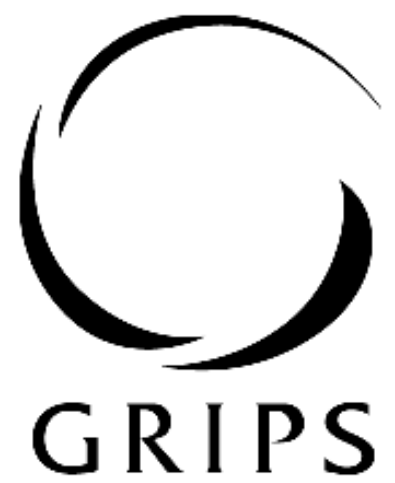

National Graduate institute FOR POLICY STUDIES

National Graduate Institute for Policy Studies

7-22-1 Roppongi, Minato-ku,

Tokyo, Japan 106-8677 


\title{
Policy Choices in Assembly versus Representative Democracy: Evidence from Swiss Communes
}

\author{
Patricia Funk \\ Università della Svizzera italiana \\ Stephan Litschig \\ National Graduate Institute for Policy Studies
}

August 2017

\begin{abstract}
This paper investigates whether the form of the legislative institution - assembly versus parliament - affects the level and composition of local public expenditure. We collect data at the commune level in Switzerland over the period 1945-2010 and use two research designs: fixedeffects and regression discontinuity (RD) based on local population. Analyzing communes that switched the form of their legislative institution over time, we find that introducing a parliament leads to a 12 percent increase in both general administration and education spending per capita and an increase in total spending and revenue of about 6 percent. In contrast, regression discontinuity estimates cannot be distinguished from zero for any spending category or overall. These contrasting results highlight the local nature of discontinuity estimates since population is an order of magnitude larger in our switcher sample compared to the RD sample. To understand the mechanism at play, we run a survey among assembly participants and document a sizeable under-representation of 20- to 40-year-olds as well as of women in town meetings compared to both the electorate and to voters in elections. Switching from assembly democracy to parliament thus increases the representation of two demographics that are known for their relatively high preference for education spending.
\end{abstract}

Keywords: legislative institutions, government spending

*Correspondence: Patricia Funk, Department of Economics, Università della Svizzera italiana, Email: patricia.funk@usi.ch; Stephan Litschig, National Graduate Institute for Policy Studies (GRIPS), Email: s-litschig@grips.ac.jp. We thank participants at the ASSA meetings in Philadelphia, the Barcelona GSE summer forum, the EEA meetings in Toulouse, the IIPF and seminar participants at University of Gothenburg, Stockholm University and Erlangen-Nürnberg for helpful comments. We also thank Prof. Ladner for generously sharing data and Veronica Grassi, Marian Meller and Felix Schönenberger for fantastic research assistance. The authors gratefully acknowledge financial support from the Swiss National Science Foundation (Sinergia grant 130648), the Fundació Caixa Manresa and the Severo Ochoa Programme for Centres of Excellence in R\&D (SEV-2011-0075). 


\section{Introduction}

Whether the form of the legislative institution at the local level matters for collective choices is an open and important question. Citizen assemblies (also called town meetings) are the form of government in which ordinary citizens gather to legislate. Local parliaments, on the other hand, are characterized by principals (citizens) delegating decision-making power to their agents (politicians). In order to improve governance, the World Bank and several aid-organizations have actively promoted citizen participation in local budgeting decisions for at least two decades (World Bank, 1996), while Bryan (2004) praises the virtues of town meetings in New England (US). Both legislative forms are prevalent around the world today after a surge of participatory democracy in several developing countries such as Brazil, Venezuela and India.

While citizen assemblies seem appealing not least because of their deliberative character, ${ }^{1}$ what we ultimately care about is whether they affect policy. Because attending assembly meetings is time-consuming, theory predicts low and potentially non-representative participation in assembly democracies (Osborne, Rosenthal and Turner 2000). Voting in elections on the other hand only requires a trip to the ballot box once every four years or so. Policies may therefore differ across legislative institutions because median voters differ. Yet to date very little is known about causal effects of direct democracy compared to a system of representative democracy (see TyreforsHinnerich and Pettersson-Lidbom, 2014, for a notable exception).

This paper provides some of the first evidence on the effects of legislative form on the level and composition of public expenditure. The setting is one of a mature democracy (Switzerland), where representative and assembly democracy coexist at the local level. Our first analysis focuses on cantons where communes have the authority to determine the form of their legislative power. ${ }^{2}$ To

\footnotetext{
${ }^{1}$ Deliberation may motivate citizens to participate in town meetings, may affect their information levels, and also their opinions on specific issues (Ban et al, 2012; Wantchekon et al, 2017).

${ }^{2}$ Cantons represent the second and communes the third tier of government in the Swiss federal system.
} 
get information on the commune's current and past legislative forms, we sent our own survey ("legislative survey") to all municipalities in these cantons. Based on this survey and other available information, ${ }^{3}$ we identified our "switcher sample" - 77 communes that changed the form of their legislative institution at least once between 1945 and 2010, most of them abolishing the assembly in favor of introducing a parliament. We focus on such switcher communes because communes that always had an assembly or a parliament are likely different from each other in partly unobservable dimensions. We did our own data collection in local archives of switcher communes in order to recover historical public expenditure information. The second analysis exploits a cantonal law (in the canton Vaud) that prescribes a parliament for communes with more than 800 inhabitants and lets voters choose their legislative power for communes with up to 800 inhabitants. We identify the effect of legislative organization on spending using a fuzzy regression discontinuity (RD) design that pools together administrative data from 5 legislative periods from 1986 to 2005 .

Our switcher sample estimates suggest that introducing a parliament leads to an increase in both general administration spending and education spending of about 12 percent in per capita terms. For other spending categories, such as welfare, law enforcement, health, and traffic and environment we find typically smaller and statistically insignificant effects. Total spending and revenue increase by about 6 percent. The causal interpretation of these estimates hinges on the assumption that time-varying unobservables are uncorrelated with parliament adoption within communes over time. Results are robust to including time-varying controls for population size and demographic composition. Introducing a commune-specific time trend leaves our results unaffected or increases the size of estimated impacts. We further probe our findings by investigating preadoption effects (which are small and insignificant) and estimating models with leads of varying length (which also yield small and insignificant effects).

\footnotetext{
${ }^{3}$ Administrative data for certain cantons and previous surveys conducted by political scientists (see Section 3 for further information).
} 
The positive impact of representative democracy on administrative spending is consistent with rent-extraction (Persson and Tabellini 2000), but also with a mechanical increase due to newly paid salaries for members of parliament and their staff. The positive impact on education spending suggests that preferences for this type of spending are systematically under-represented in assembly democracy, which is consistent with predicted low and potentially non-representative assembly turnout due to participation costs (Osborne, Rosenthal and Turner 2000). Voting costs for Swiss elections in contrast are particularly low because many cantons introduced postal voting over the course of our study period (Funk 2010).

To better understand the socio-demographic characteristics of the median voter in assemblies and elections, we also ran an "assembly survey" in which we investigated assembly participants' gender, age, education, family status and working hours. Results suggest a sizeable under-representation of 20- to 40-year-olds as well as of women in assemblies compared to both the electorate and to voters in elections. Switching from assembly democracy to parliament thus increases the representation of two demographics that are known for their relatively high preference for education spending. ${ }^{4}$

In contrast to the switcher sample estimates, regression discontinuity estimates cannot be distinguished from zero for any spending category or overall. The zero effect in our RD analysis is unlikely to be driven by an invalid research design since there is no evidence of manipulation of the running variable (commune population) and no evidence of discontinuities in observable determinants of local spending choices, such as demographic structure, labor force participation or the share of foreigners in the commune. Moreover, the first stage is sizeable (about 35 percentage points) and highly significant. We are also not aware of other policies or regulations in the canton

\footnotetext{
${ }^{4}$ See Figlio and Fletcher (2012) for a summary of the mostly U.S.-based literature on the share of elderly and support for public education spending and Cattaneo and Wolter (2009) for evidence on Switzerland. See Carruthers and Wanamaker (2015) for a summary of the evidence on women's greater preference for both private and public goods and services that enhance child welfare.
} 
Vaud that are based on the same population threshold, so the exclusion restriction likely holds in our setting.

We explain the zero effect in the RD sample primarily with commune size since average population is an order of magnitude larger in the switcher sample. The principal-agent problem might be less severe in smaller communes due to stronger social control mechanisms, which may explain why administrative spending does not increase with the adoption of parliament. Similarly, politicians (and possibly also assembly participants) are more likely to take into account preferences of non-voters (non-participants) in smaller communes (Ladner and Bühlmann, 2007), which may explain the small point estimates on other spending categories. ${ }^{5}$ The sizeable effects of legislative organization on spending composition for medium-sized but not for small communes highlight the local nature of discontinuity estimates even in a common institutional setting.

Our paper most directly relates to Tyrefors-Hinnerich and Pettersson-Lidbom (2014) who compare welfare spending under assembly and representative democracy in early 20th century Sweden after the introduction of universal and equal suffrage using an RD design based on local population. The main result is that parliaments spend 40 to 60 percent more on public welfare, and the evidence points to elite capture in assemblies (where voting is typically non-anonymous while voting in elections is anonymous) as the principal mechanism. While we do not find any effects on welfare spending in either sample this is not very surprising since elite capture is likely a minor issue in Switzerland during our study period. ${ }^{6}$

Two other recent studies investigate the related question whether citizen assemblies lead to a different resource allocation compared to referenda. Beath, Christia and Enikolopov (2017)

\footnotetext{
${ }^{5}$ Another explanation is that fuzzy RD-estimates recover an average effect for complier communes - those that adopt parliament because the rule forces them to do so, while our switcher analysis identifies a broader average effect.

${ }^{6}$ A recent paper (Sanz, 2017) investigates the effect of direct democracy on total spending for very small communes. Sanz (2017) employs an RD design (population threshold at 100 inhabitants), and deals with the fact that the density of population size is discontinuous at the cutoff. His results point towards a negative effect of direct democracy on total spending (different spending categories are not analyzed).
} 
and Olken (2010) compare the types of projects chosen under citizen assemblies and secret ballot referenda, where villagers directly vote on projects. Both studies take place in developing countries (Indonesia in Olken, 2010, and Afghanistan in Beath, Christia and Enikolopov, 2017). While referenda not only diminish the influence of elites on chosen projects (this result comes out more clearly in Beath et al.), they also lead to significantly higher citizen satisfaction. Again, a key difference between these papers and ours is the setting: Switzerland has been a mature democracy since long before 1945 and elite capture is likely to be absent.

Apart from the direct link to the before-mentioned literature on local direct democratic institutions, our paper also relates to a recent strand of literature using credible identification strategies to estimate the causal effect of electoral institutions on a variety of policy outcomes (e.g. Miller, 2008; Fujiwara, 2015; Hainmüller and Hangartner, 2015; León, 2017). And finally, our paper adds to a sizeable literature analyzing direct democratic elements (initiatives and referenda) within representative governments (see Matsusaka, 2004, for an overview of the earlier literature).

The paper is organized as follows. Section 2 presents institutional background on the Swiss federal system. Section 3 describes the data. Section 4 discusses identifying assumptions and the estimation approach for our two research designs. Section 5 presents estimation results. Section 6 provides evidence on mechanisms. Section 7 concludes.

\section{Institutional background}

\subsection{Communal autonomy}

Switzerland is a federal state with three layers of government: the federal level, the cantonal level, and the communal level. Political responsibilities remain with the cantons unless they were granted to the federal government in a national referendum. As a consequence, cantons have a lot 
of autonomy in the provision of public goods and the choice of political institutions. The degree of communal autonomy is regulated by canton laws, which leads to substantial heterogeneity across cantons. For instance, some cantons mandate political institutions at the commune level, while other cantons let the communes choose freely.

For our commune-fixed-effect analysis we focus on the fourteen cantons that allow local choice of the legislative institution (see online Appendix Table 1). ${ }^{7}$ We exclude communes from canton Ticino, since most of the local institutional variation was generated by commune mergers. Other cantons, such as Neuchâtel and Geneva, prescribe a parliament for all communes or mandate that legislative decisions at the local level are made at the assembly or at the ballot box (cantons Appenzell Innerrhoden, Appenzell Ausserrhoden, Glarus, Nidwalden, Obwalden, Schwyz, Uri).

For our RD analysis we use communes from the canton Vaud, where the legislation prescribes a parliament for communes with more than 800 inhabitants and allows local choice between parliament and assembly for communes with up to 800 inhabitants. ${ }^{8}$ Population thresholds also exist for communes in cantons Fribourg, Vallis and Zürich, which are included in our fixed-effect analysis, but the number of communes around these cutoffs is small and the assignment rule sometimes differs, mandating an assembly below the cutoff and allowing choice above.

\subsection{Commune responsibilities}

In addition to the heterogeneity in communal autonomy across cantons, the distribution of responsibilities for communal and cantonal public service provision also differs across cantons. Typically, however, commune responsibilities include preschool and primary education (grades 1 through 5 or 6), welfare, law enforcement, and traffic, among others. For the medium-sized communes in

\footnotetext{
${ }^{7}$ In all but one canton (Schaffhausen) there were actual switches of legislative institutions during our sample period.

${ }^{8}$ In 2005 the cutoff was raised from 800 to 1,000 inhabitants.
} 
our switcher sample, responsibilities typically also include lower secondary education (grades 6 or 7 through 9). The bulk of communal spending is on education, welfare, traffic and general administration (Tables 1 and 2). As for total communal spending relative to cantonal and federal spending, communes undertook $24 \%$ of total spending, the cantons $42 \%$, and the federal level the remaining $34 \%$ in the year 2010. A large share of local expenditures is financed through a local income tax.

\subsection{Commune organization and political rights}

Decision-making bodies at local level include the executive (usually called Gemeinderat), the legislative, organized as either assembly or parliament, the electorate, and special committees for example for financial affairs. The exact division of powers in the budget process varies across communes but typically it is characterized as follows. The executive implements approved expenditures and drafts the budget proposal in consultation with the finance committee. The legislative votes on the budget proposal and controls the execution of past expenditures. Participants at assemblies can propose budgetary items for deliberation. Budgetary decisions are taken by simple majority in an open vote, except if a secret vote is requested and approved. Under both legislative forms, the final say on the budget may rest with the electorate, either through mandatory or facultative referendum - that is, when a sufficient number of citizens ask for a vote at the ballot box. 


\section{Data}

\subsection{The switcher sample}

To gather information on the institutional history of today's 2,551 Swiss communes, we sent an e-mail with a link to an online survey to all municipal secretaries on April 272011 . We asked for information about the organization of the legislative since 1945, but also for other institutional information (presence of initiative and referendum rights and corresponding changes since 1945). After sending reminder e-mails and calling 1,120 communes, we obtained a survey response rate (complete or partial) of $48.6 \%$ for our study cantons (see online Appendix Table 1).

From the 881 communes that responded to our survey there were 32 that had changed the form of their legislative power between 1945 and 2010. For 25 switchers, we had all the necessary information (year of the switch), because they had completed the relevant survey module. For 7 communes, we were missing the precise year of the switch. To gather this missing information, we checked available local constitutions or called up the commune secretaries. For the $51.4 \%$ of non-responders and another 129 respondents that only gave the current status of the legislative power, we complement our analysis with previous surveys conducted by political scientists. In four different waves (1988, 1994, 1998 and 2005) Professor Ladner and his team elicited detailed information on the political structure (including legislative form) of local governments.

As can be seen in online Appendix Table 1, response rates in these Ladner surveys were high. Most important for us is that for communes that filled out all the Ladner surveys, we can reconstruct the entire institutional history between 1945 and 2005. The reason is that the surveys did not only inquire about the current state of the legislative but also about past attempts to change the form of the legislative power. As such, if a commune answered in the 1988 survey that it had an assembly and no effort had been undertaken to introduce a parliament in the past, we 
can assume that they had an assembly all the way back to 1945. As a last source of information, we used cantonal administrative information wherever available. ${ }^{9}$

Combining these three sources of information (our survey, the Ladner surveys, and cantonal information on parliaments for four cantons) we identified 77 communes that had changed the form of their legislative power, mostly abandoning the citizen assembly in favor of introducing a parliament. As can be seen from Figure 1, the switcher sample is spread out all over Switzerland. Furthermore, there is substantial heterogeneity in the time of institutional change across communes (see online Appendix Figures 1 and 2).

What were the main reasons for the system change? One of the key arguments in favour of introducing a parliament was potentially better representation. Especially in large communes, turnout in assemblies was very low (often less than 10 percent), which raised concerns about representation. Frequently heard arguments against having parliaments were a potentially stronger influence of political parties and lobbyists. Since a commune's population size may be a key factor for the decision to adopt a parliament, we control for population size in the regressions.

\subsection{Local budgetary data for the switcher sample}

Since standardized data in electronic format was only available for a subset of cantons for the more recent years (starting in 1980 or 1990), most of the budgetary data had to be collected in the field. This required first contacting each of the 77 sample communes (by phone and/or e-mail), to ask for access to their local archives, and then to make all the necessary arrangements for the archive visit. This process often involved several steps, and in some cases even involved formal requests to the local executive body, as access to the archive was first denied. Arrangements were made

\footnotetext{
${ }^{9}$ For the canton Freiburg, we know the communities with a parliament today (15), and also the year it was introduced. For the cantons Aargau, Valais and Zuerich, we got a list of all communities that have or ever had a parliament. Since we did not know the year in which the parliament was introduced (and/or potentially abolished), we checked the websites for these communes or called them up to get this missing information.
} 
with the head of the financial department, the municipal clerk, or the municipal archivist. The efforts required for reviewing the documents varied by commune and depending on canton-specific transparency laws. In the end, we managed to get access to every single communal archive in our switcher sample. Only a few communes had missing information, mostly for earlier years.

We collected data on total revenue and total expenditure, as well as expenditures broken down by spending category. This so-called functional division classifies expenditure items by the service categories carried out by the commune. Harmonizing the categories for functional expenditure over time and across communes was a major challenge. By 2010, the financial accounting systems of cantons and communes were largely standardized according to the Harmonized Accounting Model (HAM-1) and applied all over Switzerland (most communes adopted the HAM-1 in the 1980s). In earlier years, however, accounting systems varied across cantons and time, and even slightly within cantons.

To be as consistent as possible, we proceeded as follows: (a) If the sub-division in the raw data for earlier years was more detailed than under the later HAM-1, we aggregated the items into the corresponding HAM-1-category, as close as possible in line with official guidelines. (b) If the data was more aggregated than the HAM-1 (e. g. "Education" and "Public Security and Health" together), we adopted the coinciding category (Education), and set missing values for the nonseparable categories (Public Security; Health). (c) In the years prior to the HAM-1, it is generally not possible to sharply disentangle the two HAM-1-categories "Traffic" and "Environment and Spatial Planning", but we can at least identify the items that would correspond to either of the two under the HAM-1. We summarize all these items by the single meta-category "Traffic and Environment", which simply becomes the sum of the two HAM-1-categories from the 1980s. We coded every change in the commune's accounting system and control for these structural breaks using dummy variables in the regressions. 


\subsection{The RD sample}

For the sake of comparability, our RD analysis is based on a population range from 400 to 1,200 inhabitants, i.e. +/- 400 around the 800 cutoff. Local population is based on administrative data from the population office of canton Vaud. The reference population for the 4-year legislative period from year $t$ to $t+3$ is population at the end of year $t-2$, with elections being held in the fall of year t-1. We identified commune-years with reference population in the 400-1,200 interval for the five legislative periods 1986-1989, 1990-1993, 1994-1997, 1998-2001, 2002-2005. We exclude more recent legislative periods because the cutoff for local legislative form choice was raised to 1,000 inhabitants in 2005. For communes in the 400-800 interval, we determined the status of the legislative power using communal constitutions and minutes from actual assemblies and parliament sessions. For those in the 801-1,200 interval we simply impute a parliament after doing some crosschecks, again using local constitutions and session minutes. For communes from the canton Vaud, local budgetary data are available from the statistical office starting from 1985.

Tables 2 and 3 show the budget categories we use in our switcher- and RD-analysis, respectively. In the switcher sample the largest budget category is education, followed by traffic and environment and welfare, while in the RD sample education spending is most important, followed by administrative spending and an aggregate welfare and health spending category. Note that the period of observation for the budgetary data from Vaud covers the 4-year legislative cycle, while in the switcher sample the data are annual. Since we run all regressions in logs, level differences across the two samples are inconsequential for interpretation of the results. Other budget categories, such as "Properties and Buildings" or "Construction", are only available in either the switcher or the RD sample. There is no impact of parliament adoption on these other categories. Results are available on request. 


\subsection{Political participation survey}

One key difference between assembly and representative democracy is the level of political participation or turnout. Indeed, our leading hypothesis is that turnout increases when parliamentary elections are introduced, which in turn may alter the median voter's preferences. Ideally, we would therefore like to provide direct evidence on political participation from our switcher sample at different points in time. Unfortunately however, there are no historical data on turnout in assemblies or in local legislative elections. We draw instead on a recent country-wide survey of municipal clerks (Ladner 2009) that inquired about patterns of participation in assemblies and local executive elections. While turnout is only available for local executive - not legislative - elections, we verified for recent elections in our switcher sample that local executive and legislative turnout are highly correlated (results available on request). We therefore think it is reasonable to assume that similar participation patterns also characterized earlier periods.

\subsection{Assembly survey}

In order to understand whether assembly participants differ from voters in elections and from the electorate at large, we conducted our own survey in canton Zürich communes during the fall of 2016. Out of the 154 communes in canton Zürich with a citizen assembly, 62 agreed to participate in the survey. We decided to gather assembly participants' characteristics at the "budget" assembly, which is when the upcoming year's budget is decided.

At the start of the assembly, the municipal clerk explained to participants that the survey was part of a study financed by the Swiss national science foundation investigating the functioning of citizen assemblies. The municipal clerk also encouraged assembly participants to fill out the survey, explaining that anonymity was guaranteed and that the survey would take less than five minutes to fill out. The survey itself consisted of two pages and asked about gender, age, family 
status, education and labor market status. The municipal clerk counted the total number of assembly participants so that we could assess the response rate, which was 66 percent on average. As a robustness check we also looked only at communes with response rates larger than 70 percent and found quantitatively similar results (available on request).

\subsection{Electorate characteristics}

From the statistical office of canton Zürich we obtained information on the set of individuals eligible to vote (Swiss citizens, aged 18 years and above). Data on age are administrative and cover the entire population of the canton, while data on education, family structure and hours worked are collected as part of an annual survey ("Strukturerhebung") run jointly by the federal government and cantonal authorities. ${ }^{10}$ We aggregate each variable across all individuals living in the 62 communes that participated in our assembly survey.

\subsection{Voter characteristics}

Local parliament elections take place every four years and voting is either done by mail or at the ballot box. Because there are no commune-level surveys of voter characteristics, we rely on postnational-election surveys (Swiss Electoral Studies) that are representative at the cantonal, not local level. Respondents were contacted in the weeks following an election and asked information on gender, age, education, income, and civil status. ${ }^{11}$ We combine the 2011 and 2015 survey rounds to obtain a total sample size of 1,127 respondents who participated in the respective preceding national elections.

\footnotetext{
${ }^{10}$ See https://www.bfs.admin.ch/bfs/de/home/statistiken/bevoelkerung/erhebungen/se.html for further information.

${ }^{11}$ Until the year 2011, interviews were done by telephone, and starting from the election in 2015, the researchers use both telephone and online methods. A description of the surveys and all the data can be found on the following webpage: http://forscenter.ch/en/our-surveys/selects/.
} 
One natural question is whether voters in national elections differ from voters in cantonal or local elections. To address this concern, we exploit an earlier post-national-election survey from 2007 that asked about participation in both federal and cantonal elections. Comparing the characteristics of voters in federal and cantonal elections, we find that they are almost identical (results available upon request). Moreover, an even earlier survey from 2003 asked about respondents' interest in local and cantonal politics on a scale from one to four. Among voters in cantonal elections, average interest in local politics was 2.88 , while for cantonal politics it was 2.86 . It therefore seems reasonable to expect socio-demographic characteristics of voters in cantonal and local elections to be similar.

\subsection{Control variables}

Control variables (commune population, demographic structure, labor force participation rate, and share foreigners) are from the Swiss Federal Statistical Office (Bundesamt für Statistik). Control variables are interpolated between census years, except for commune population which is based on yearly administrative data for the canton Vaud and for the switcher sample between 1981 and 2010. As can be seen from the summary statistics in Tables 1 and 2, the communes of canton VD are comparable to the communes in the switcher sample in terms of age structure, labor force participation or the share of foreigners. However, the communes in the RD sample are much smaller compared to the communes in the switcher sample (a mean of 688 inhabitants versus a mean of 8,532 inhabitants). 


\section{Identification and estimation approach}

\subsection{Fixed-effects analysis}

Let $Y_{c t}$ denote spending in a given category in commune $c$ and period $t, D_{c t}$ the indicator for parliament (1) or assembly (0), $\beta$ the (constant) effect of parliament relative to assembly, $X_{c t}$ commune population, demographic controls (share of population in age brackets 20-39, 40-64, 65 and above), labor force participation rate and share foreigners, $\alpha_{c}$ commune fixed-effects, $\gamma_{t}$ time fixed-effects, and $U_{c t}$ the influence of unobserved additional factors that affect outcomes. The baseline specification is as follows:

$$
\ln \left(Y_{c t}\right)=\beta D_{c t}+\delta X_{c t}+\alpha_{c}+\gamma_{t}+U_{c t}
$$

The causal interpretation of fixed-effects estimates hinges on the assumption that time-varying unobservables are uncorrelated with parliament adoption, conditional on the commune- and time fixed-effects and time-varying controls. We control for population to address the concern that the likelihood of parliament adoption increases with population size. We also control for commune demographics since the age profile of the population is a potential determinant of public spending priorities, as are labor force participation and the share foreigners in the commune. Results without time-varying controls are quantitatively similar and are available on request. Our second specification additionally controls for commune-specific linear trends $\theta_{c} t$. The third specification in addition controls for commune-specific breaks in the local accounting system.

We further probe our findings by estimating models with leads and lags of varying length:

$$
\ln \left(Y_{c t}\right)=\beta_{0} D_{c t}+\sum_{l=1}^{L} \beta_{-l} D_{c t-l}+\sum_{f=1}^{F} \beta_{+f} D_{c t+f}+\delta X_{c t}+\alpha_{c}+\gamma_{t}+U_{c t}
$$


We test the joint significance of the $L$ lags and $F$ lead coefficients separately. The test on the lags tells us whether part of the impact of parliament on spending occurs with a lag. The test on the leads tells us whether introducing a parliament in the future already has effects on spending today, which is possible due to anticipation effects, or more worrisome, due to endogeneity of adoption.

As a final robustness check on pre-adoption effects, let $\operatorname{Pre}_{c t-\tau}$ denote a dummy variable equal to 1 for each of $\tau$ pre-adoption years. The omitted category is thus assembly periods other than those covered by $\operatorname{Pre}_{c t-\tau}=1$. The model is as follows:

$$
\ln \left(Y_{c t}\right)=\beta D_{c t}+\beta_{-\tau} \operatorname{Pre}_{c t-\tau}+\delta X_{c t}+\alpha_{c}+\gamma_{t}+\theta_{c} t+U_{c t}
$$

We let $\tau$ range from 1 to 4 and for each specification test the hypothesis that the post-adoption effect is the same as the pre-adoption effect $\beta=\beta_{-\tau}$.

\subsection{RD design}

The basic intuition behind the regression discontinuity design is that communes just to the left of the 800 population cutoff should provide valid counterfactual outcomes for communes just to the right of the cutoff where parliament is mandatory. More formally, let $Z_{c t}=I\left[p o p_{c t}>800\right]$ denote the indicator for being above the population cutoff, $p o p_{c t}$ commune population, $f\left(\right.$ pop $\left._{c t}-800\right)$ and $g\left(\right.$ pop $\left._{c t}-800\right)$ linear or quadratic splines in normalized population, and $V_{c t}$ the influence of unobserved additional factors that affect parliament adoption, in addition to $Z$. The model is as follows:

$$
\begin{aligned}
\ln \left(Y_{c t}\right) & =\beta D_{c t}+f\left(\text { pop }_{c t}-800\right)+U_{c t} \\
D_{c t} & =\pi Z_{c t}+g\left(p o p_{c t}-800\right)+V_{c t} .
\end{aligned}
$$


If $E[U \mid p o p]$ and $E[V \mid p o p]$ are continuous, the exclusion restriction holds, and if there is a first stage $(\pi>0)$, then the ratio of the reduced-form coefficient divided by the first stage coefficient $\pi$ identifies $\beta{ }^{12}$ Throughout the paper, we focus on reduced form estimates in order to maintain a close correspondence with the graphical evidence.

Intuitively, the continuity assumption requires that unobservables vary smoothly as a function of commune population and, in particular, do not jump at the cutoff. As shown in Lee and Lemieux (2010), sufficient for the continuity assumption is the assumption that individual densities of the treatment-determining variable are smooth. In our case, this assumption explicitly allows for communes to have some control over their particular number of inhabitants. As long as this control is imprecise, treatment assignment is essentially randomized around the cutoff. Precise control over resident population is unlikely because local population is recorded by cantonal and not communal authorities. We are also not aware of other policies or regulations in the canton Vaud that are based on the 800 population threshold, so the exclusion restriction likely holds in this setting.

\section{Estimation results}

\subsection{Switcher sample results}

Table 3 shows estimation results of equation (1) for spending categories in the switcher sample. Introducing a parliament increases administrative spending and education spending per capita by about 12 percent in the most demanding specification with commune-specific time trends and structural break dummies. The estimate on health spending per capita is of the same order of

\footnotetext{
${ }^{12}$ With heterogeneous treatment effects and imperfect compliance, the ratio of RD-gaps identifies a local average treatment effect "close" to the cutoff. This result requires the monotonicity assumption which in our case says that communes that adopted a parliament with population below the cutoff would have also adopted parliament had their population been above the cutoff. This seems uncontroversial.
} 
magnitude but imprecise. Impact estimates for welfare, law enforcement and traffic and environment spending are all small and statistically not significant. Overall, total spending and revenue increase by about 6 percent (result available on request).

Table 4 presents results from equation (2), testing whether introducing a parliament in the future already has effects on spending in the present and whether part of the impact arises with a lag. The estimates of the dynamic cumulative 4-year effect (sum of contemporaneous and four lagged coefficient estimates) for administrative and education spending are only slightly larger than the impact estimates in Table 3, suggesting that essentially the entire effect is realized on impact. ${ }^{13}$ There is no evidence of impacts arising with a lag for other spending categories either, except perhaps for positive estimates on health spending and negative estimates on traffic/environment spending that are both marginally significant at 10 percent. Turning to the cumulative preadoption effects (sum of four lead coefficients), Table 4 shows that these estimates are uniformly small and insignificant across spending categories and specifications.

Table 2 in the online Appendix shows results from estimating equation (3) where in addition to the indicator variable (parliament 0/1), dummies for time-periods prior to the legal change are included. Pre-adoption effects are small and statistically insignificant for all spending categories. Moreover, for administrative and education spending, we can reject the null hypothesis that the effect on spending $\tau$ periods prior to adoption is the same as after the adoption. Overall, the econometric evidence strongly suggests that estimates of the effect of adopting a parliament on education and administrative spending in the switcher sample are causal.

\footnotetext{
${ }^{13}$ Specifications with alternative lead- and lag-lengths are quantitatively similar and available on request.
} 


\section{$5.2 \quad \mathrm{RD}$ sample results}

We now turn to the regression discontinuity analysis of parliament adoption on budget allocation in canton Vaud. Before comparing spending of communes around the 800 population cutoff, we visually check whether there is sorting around the threshold. Figure 2 confirms that there is no bunching on either side of the threshold and the McCrary density test gives a log difference in height at the cutoff of -.035 with standard error 0.276. In addition, Table 5 shows that observables appear continuous at the 800 population cutoff. Overall, these results are consistent with the smooth density assumption required for identification.

We proceed with estimating the first stage coefficient $\pi$ in equation (5). As shown in Table 6 first row (and visualized in Figure 3), the probability of having a parliament jumps by about 35 percentage points for communes with 801 compared to those with 800 inhabitants. Comparing now different types of spending at the cutoff, Table 6 shows that the reduced form estimates fluctuate around zero and are insignificant throughout with only one exception (see also Figures 4 and 5 for administrative and education spending, respectively). Implied instrumental variable estimates of parliament adoption can be obtained by multiplying the reduced form estimates by three. Results using optimal bandwidths as proposed by Imbens and Kalyanaraman (2012) as well as bias-corrected estimates and robust standard errors proposed by Calonico, Cattaneo and Titiunik (2014) are similar and available on request.

We conclude that the effect of representative (versus assembly) democracy on spending is essentially zero in small communes, although the standard errors are admittedly quite large and we cannot rule out sizeable effects in either direction. While we cannot reject that the effects for administrative and education spending are the same across the RD and switcher samples, the patterns are clearly different - RD estimates bounce around zero while fixed-effects estimates are consistently positive. Overall, these results highlight the local nature of discontinuity estimates 
since population is an order of magnitude larger in our switcher sample compared to the RD sample.

\section{Mechanisms}

What are likely mechanisms driving these result, starting with the positive effect on education spending in the switcher sample? Our leading hypothesis is that turnout increases when parliamentary elections are introduced and that this induces a shift towards a pivotal voter with higher preferences for education spending. Figure 6 supports the first step in this causal chain, documenting that turnout in communal executive elections is indeed an order of magnitude higher than participation in assemblies for a large sample of communes from all over Switzerland.

Moving to our assembly survey results from canton Zürich, Panel A of Figure 7 provides evidence that assembly participants are significantly older than the electorate in communes that participated in our assembly survey. As is evident from that figure, 20- to 40-year-olds are particularly under-represented in those communes. While the average Swiss citizen is 50.9 years old, average age of assembly participants is 57.1. Panel B of Figure 7 shows that 20- to 40-year-olds are under-represented in assemblies also compared to canton Zürich voters who participated in national elections (the average voter is 52.8 years old).

In addition, Panel A of Figure 8 shows that women are under-represented in assemblies compared to their proportion in the electorate in the set of communes that participated in our assembly survey. While the proportion of females among Swiss citizens is about 0.51, the proportion of female assembly participants is only 0.40. Similarly, Panel B of Figure 8 shows that women are also under-represented in assemblies when compared to canton Zürich voters in national elections in which about 48 percent are female. Results for other characteristics are less clear-cut. For example, Figure 3 in the online Appendix shows that the average level of education is similar 
among assembly participants and canton Zürich voters in national elections.

A natural concern is whether these results generalize beyond canton Zürich. We again take advantage of the 2009 survey of municipal clerks, who were asked about their subjective opinion regarding which groups of people are over- or under-represented at assemblies in their commune. Reassuringly, we find that municipal clerks tend to view young people and women as being underrepresented at assemblies, while highly-educated people seem to be proportionally represented (results available on request). Together, these results suggest that switching from assembly democracy to parliament tends to increase the representation of women and middle-aged citizens, two demographics that are known for their relatively high preference for education spending (Figlio and Fletcher 2012, Cattaneo and Wolter 2009, Carruthers and Wanamaker 2015).

Turning to our explanation for the zero effect in the RD analysis, we think that the main reason is commune size: average commune size is 8,532 in the switcher sample (Table 1 ), but a mere 688 in the canton Vaud (Table 2). The principal-agent problem is therefore likely less severe in smaller communes due to stronger social control mechanisms, which may explain why administrative spending does not increase with the adoption of parliament. Similarly, politicians (and possibly also assembly participants) are more likely to take into account preferences of nonvoters (non-participants) in smaller communes (Ladner and Bühlmann 2007), which may explain the zero effect on other spending categories.

\section{Conclusion}

We have empirically investigated whether the choice of legislative institution matters for the level and composition of local government spending in Switzerland over the period 1945-2010. Our answer is mixed: the form of the legislative does not seem to matter for small communes, but it matters for medium-sized communes. We find that introducing a parliament leads to a 12 percent 
increase in both general administration and education spending per capita and a 6 percent increase in total spending and revenue. While rent seeking and the cost of running a parliament can explain the increase in administrative spending, they are unlikely to account for the increase in education spending. A more likely mechanism is a change in the identity and preferences of the pivotal voter. Legislative elections (compared to assemblies) increase the representation of middle-aged citizens and women, two groups that tend to be relatively favorable to public spending on education. Overall, these results suggest that the form of the local legislative institution matters for budget allocation and that the benefits of direct citizen participation may come at the cost of selective representation. Future research might therefore investigate ways to give under-represented groups more voice in the assembly decision-making process. 


\section{References}

Ban, R., S. Jha and V. Rao, 2012,"Who Has Voice in a Deliberative Democracy? Evidence from Transcripts of Village Parliaments in South India," Journal of Development Economics, 99(2): $428-438$.

Beath, A., F. Christia and R. Enikolopov, 2017, "Direct Democracy and Resource Allocation: Experimental Evidence from Afghanistan," Journal of Development Economics, 124: 199213.

Bryan, F. M., 2004, "Real Democracy. The New England Town Meeting and How it works.," The University of Chicago Press.

Carruthers, C. K. and M. H. Wanamaker, 2015, "Municipal Housekeeping: The Impact of Women's Suffrage on Public Education," Journal of Human Resources, 50(4): 837-871.

Cattaneo M. D., Calonico, S. and R. Titiunik, 2014, "Robust Nonparametric Confidence Intervals for Regression-Discontinuity Designs," Econometrica 86(2): 2295-2326.

Cattaneo, M. A., Wolter, S. C., 2009, "Are the elderly a threat to educational expenditures?" European Journal of Political Economy, 25: 225-236.

Figlio, D. N. and Fletcher, D., 2012, "Suburbanization, demographic change and the consequences for school finance," Journal of Public Economics, 96(11-12), 1144-1153.

Fujiwara, T., 2015, "Voting Technology, Political Responsiveness, and Infant Health: Evidence from Brazil," Econometrica, 83(2): 423-464.

Funk, P., 2010, "Social Incentives and Voter Turnout: Evidence from the Swiss Mail Ballot System," Journal of the European Economic Association, 8(5): 1077-1103. 
Hainmüller, J. and D. Hangartner, 2015, "Does Direct Democracy Hurt Immigrant Minorities? Evidence from Naturalization Decisions in Switzerland," American Journal of Political Science, forthcoming.

Imbens, G. W. and K. Kalyanaraman, 2012, "Optimal Bandwidth Choice for the Regression Discontinuity Estimator," Review of Economic Studies, 79(3): 933-959.

Ladner, A. and M. Bühlmann, 2007, Demokratie in den Gemeinden. Der Einfluss der Gemeindegrösse und anderer Faktoren auf die Qualität der Demokratie in den Gemeinden, Zürich/Chur: Rüegger.

Lee, D. S., and T. Lemieux, 2010, "Regression Discontinuity Designs in Economics," Journal of Economic Literature, 48(2): 281-355.

León, G., 2017, “Turnout, Political Preferences and Information: Experimental Evidence from Peru," Journal of Development Economics, 127: 56-71.

Lijphart, A., 1997, "Unequal Participation: Democracy's Unresolved Dilemma," American Political Science Review, 91(1): 1-14.

Linder, W., 1994, Swiss Democracy: Possible Solutions to Conflict in Multicultural Societies, New York: St. Martin's Press.

Matsusaka, J. G., 2004, For the many or the few: The initiative, public policy, and American democracy, Chicago: University of Chicago Press.

Miller, G., 2008, "Women's Suffrage, Political Responsiveness, and Child Survival in American History," Quarterly Journal of Economics, 123(3), 1287-1327.

Olken, B. A., 2010, "Direct Democracy and Local Public Goods: Evidence from a Field Experiment in Indonesia," American Political Science Review, 104: 243-267. 
Osborne, M., J. Rosenthal, and M. Turner, 2000, "Meetings with Costly Participation," American Economic Review, 90: 927-943.

Persson, T. and G. Tabellini, 2000, Political Economics: Explaining Economic Policy, Cambridge, MA: MIT Press.

Sanz, C., 2017, "Direct Democracy and Government Size: Evidence from Spain," Banco de España Working Paper Nr. 1709.

Tyrefors-Hinnerich, B. and P. Pettersson-Lidbom, 2014, "Democracy, Redistribution, and Political Participation: Evidence from Sweden 1919-1938," Econometrica, 82(3): 961-993.

Wantchekon, L., G. Lopez-Moctezuma, T. Fujiwara, C. Pe Lero and D. Rubenson, "Policy Deliberation and Voting Behavior: A Campaign Experiment in the Philippines," Mimeo.

World Bank, 1996. The World Bank Participation Sourcebook. Washington, DC: The World Bank. 


\section{Table 1: Summary statistics for the switcher sample}

\begin{tabular}{lccccc}
\hline & Obs. & Mean & Std. D. & Min & Max \\
Form of the local legislative power (authors' data collection) & & & & & \\
Parliament (1), Assembly (0) & 5.082 & 0.506 & 0.500 & 0 & 1 \\
& & & & & \\
Local budgetary data (authors' data collection) & & & & & \\
Total revenue per capita & 4.762 & 3.702 & 2.562 & 134 & 30.273 \\
Total spending per capita & 4.790 & 3.659 & 2.520 & 164 & 30.273 \\
Administrative spending per capita & 4.797 & 370 & 287 & 16 & 2.620 \\
Welfare spending per capita & 4.285 & 437 & 495 & 0 & 3.543 \\
Law enforcement spending per capita & 4.329 & 149 & 126 & 0 & 1.234 \\
Education spending per capita & 4.502 & 755 & 507 & 3 & 2.848 \\
Health spending per capita & 3.400 & 150 & 151 & 0 & 1.056 \\
Traffic and environment spending per capita & 4.680 & 632 & 650 & 0 & 7.587 \\
Control variables (Bundesamt für Statistik) & & & & & \\
Resident population & & & & & \\
Labor force participation rate (\%) & 5.082 & 8.532 & 6.052 & 404 & 29.006 \\
Share of 0- to 19-year-olds (\%) & 5.082 & 61.8 & 4.6 & 46.5 & 79.1 \\
Share of 20- to 39-year-olds (\%) & 5.082 & 11.8 & 4.4 & 2.7 & 30.0 \\
Share of 40- to 64-year-olds (\%) & 5.082 & 28.8 & 6.1 & 14.9 & 45.7 \\
Share of at least 65-year-olds (\%) & 5.082 & 30.5 & 4.2 & 13.9 & 53.0 \\
Share foreigners (\%) & 5.082 & 28.9 & 3.9 & 16.9 & 45.5 \\
\hline & 53.8 \\
\hline
\end{tabular}

Notes: The unit of observation is a commune-year. The sample period ranges from 1945 to 2010. Budgetary data are in year 2010 Swiss Francs based on the consumer price index. Control variables are from the Swiss Federal Statistical Office (Bundesamt für Statistik). Resident population is based on administrative data from 1981 to 2010 and interpolated from census data between 1945 and 1980. The other control variables are interpolated based on census data. 


\section{Table 2: Summary statistics for the RD sample}

\begin{tabular}{|c|c|c|c|c|c|}
\hline & Obs. & Mean & Std. D. & Min & $\operatorname{Max}$ \\
\hline \multicolumn{6}{|c|}{ Form of the local legislative power (authors' data collection) } \\
\hline Parliament (1), Assembly (0) & 531 & 0.555 & 0.497 & 0 & 1 \\
\hline \multicolumn{6}{|l|}{ Local budgetary data (Statistique VD) } \\
\hline Total revenue per capita & 531 & 19.189 & 5.669 & 8.472 & 69.736 \\
\hline Total spending per capita & 531 & 19.196 & 5.613 & 8.556 & 69.626 \\
\hline Administrative spending per capita & 531 & 2.378 & 938 & 695 & 7.678 \\
\hline Welfare and health spending per capita & 531 & 1.760 & 1.618 & 223 & 8.203 \\
\hline Law enforcement spending per capita & 531 & 491 & 286 & 134 & 2.894 \\
\hline Education spending per capita & 531 & 3.728 & 1.369 & 872 & 15.405 \\
\hline Traffic and environment spending per capita & 531 & 1.014 & 644 & 0.069 & 4.133 \\
\hline \multicolumn{6}{|c|}{$\underline{\text { Control variables (Bundesamt für Statistik and Statistique VD) }}$} \\
\hline Reference population & 531 & 688.6 & 216.6 & 401 & 1197 \\
\hline Labor force participation rate $(\%)$ & 531 & 64.3 & 6.9 & 36.6 & 99.0 \\
\hline Share of 0 - to 19 -year-olds (\%) & 531 & 26.4 & 3.9 & 16.3 & 41.0 \\
\hline Share of 20- to 39-year-olds (\%) & 531 & 28.3 & 4.6 & 15.7 & 51.4 \\
\hline Share of 40- to 64-year-olds (\%) & 531 & 33.0 & 4.5 & 16.4 & 52.2 \\
\hline Share of at least 65 -year-olds $(\%)$ & 531 & 13.1 & 4.5 & 2.9 & 30.0 \\
\hline Share foreigners $(\%)$ & 531 & 13.7 & 7.5 & 2.1 & 41.2 \\
\hline
\end{tabular}

Notes: The unit of observation is a commune in a 4-year legislative period. The sample period ranges from 1986 to 2005. Commune-legislative periods are included in the sample if the reference population falls within the interval $(400,1200)$. Reference population refers to the year preceding the legislative period. Budgetary data are in year 2010 Swiss Francs based on the consumer price index. Reference population is based on administrative records from the Statistical Office of canton Vaud (Statistique VD). The other control variables are interpolated based on census data from the Swiss Federal Statistical Office (Bundesamt für Statistik). 


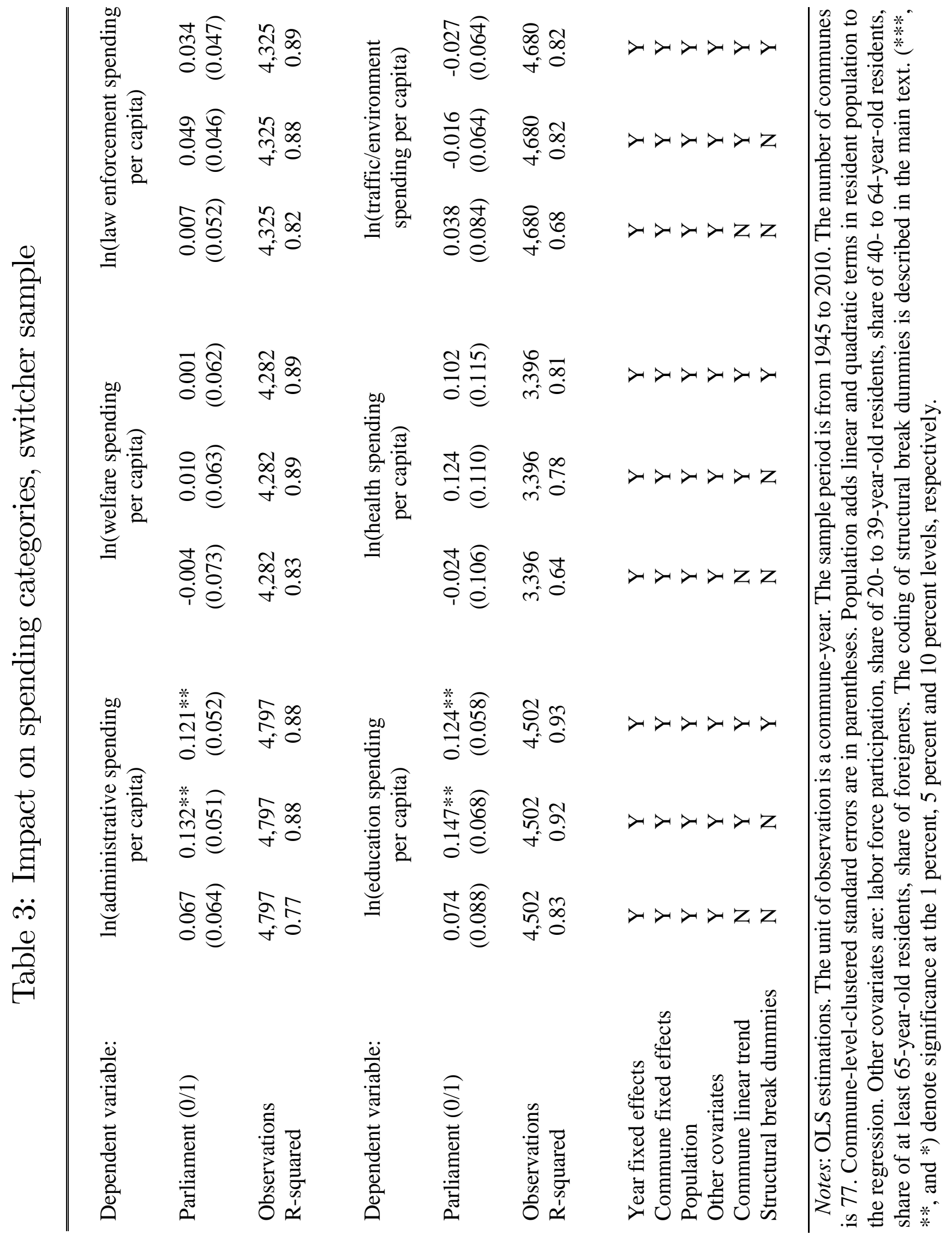




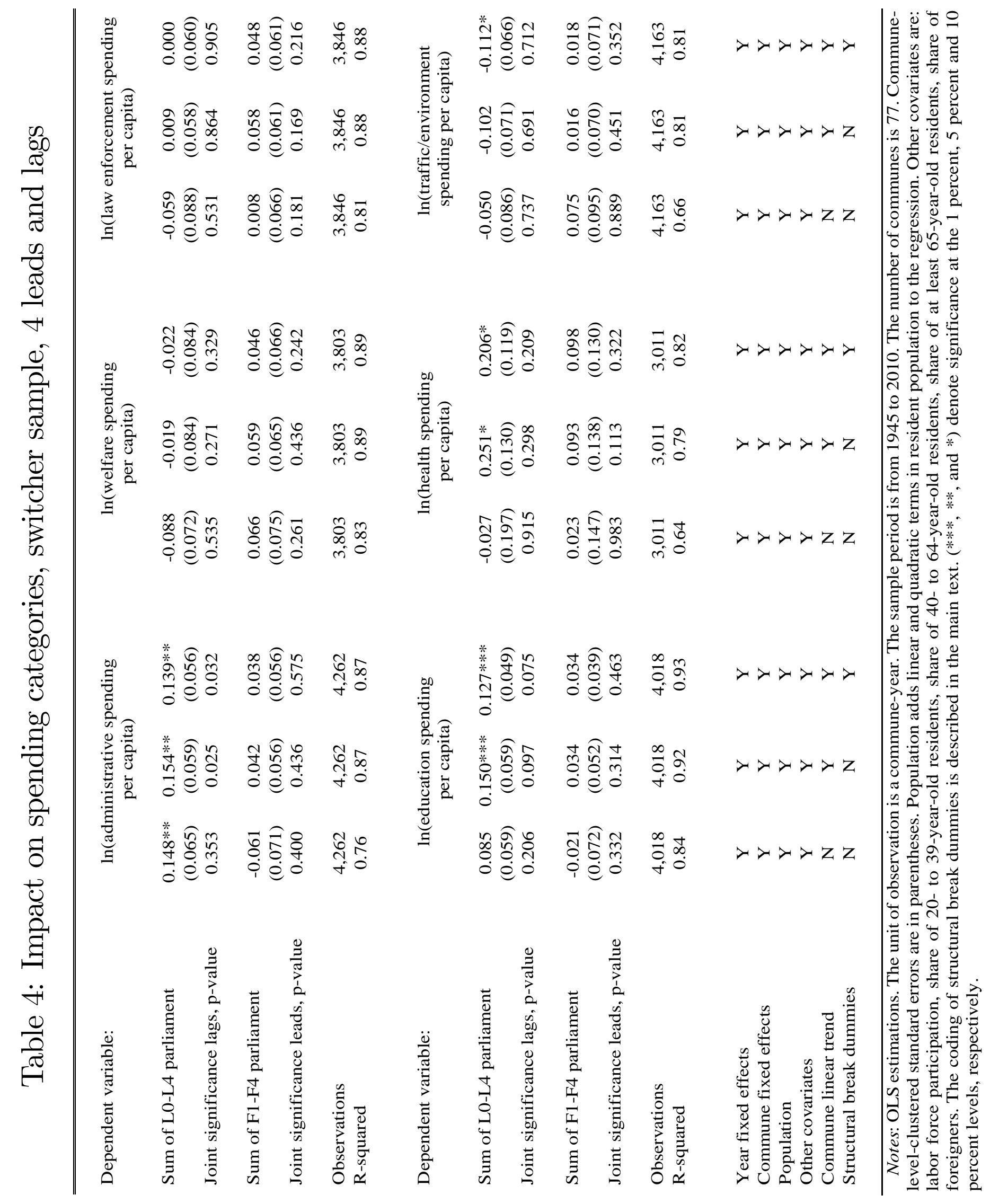




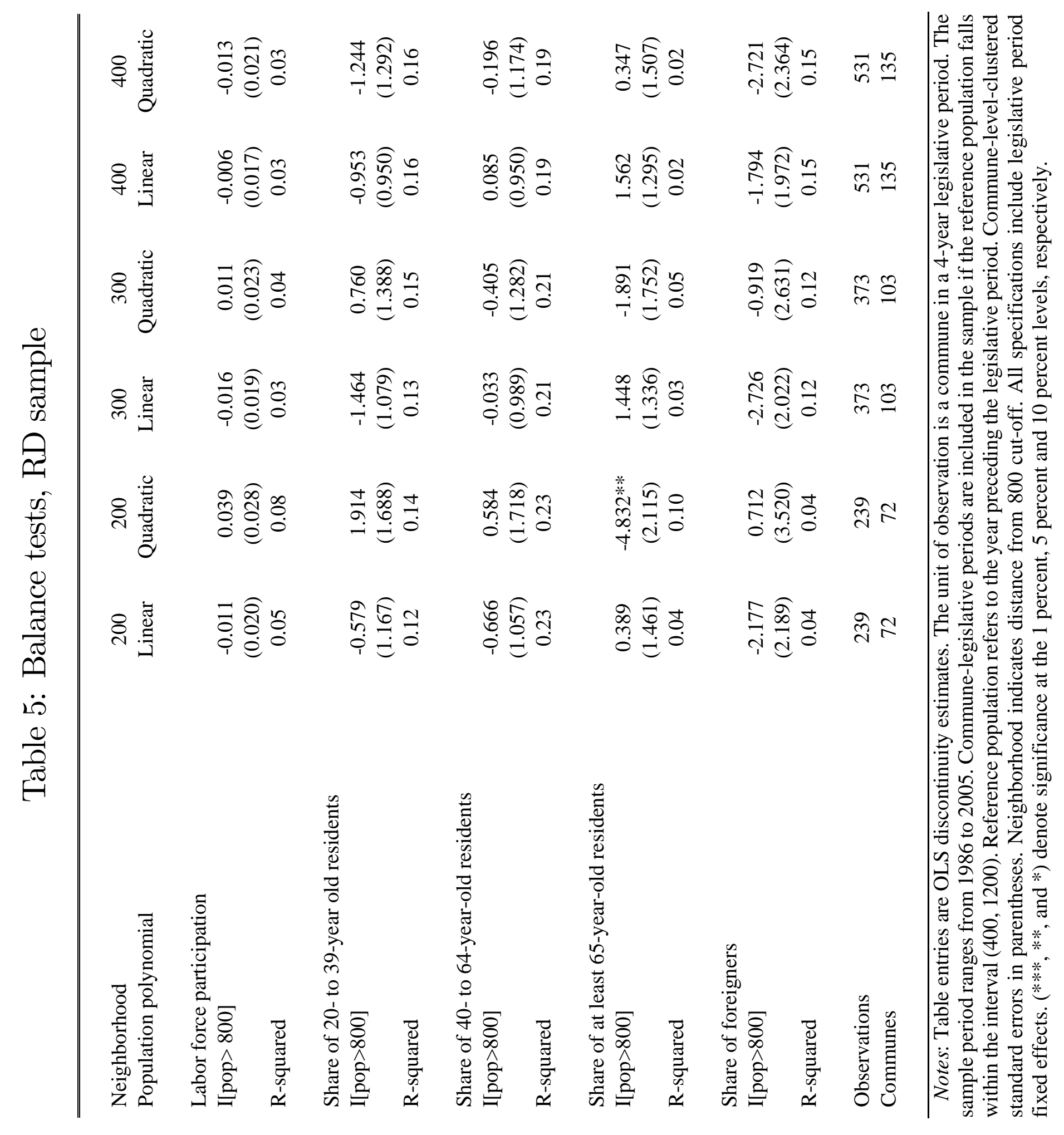




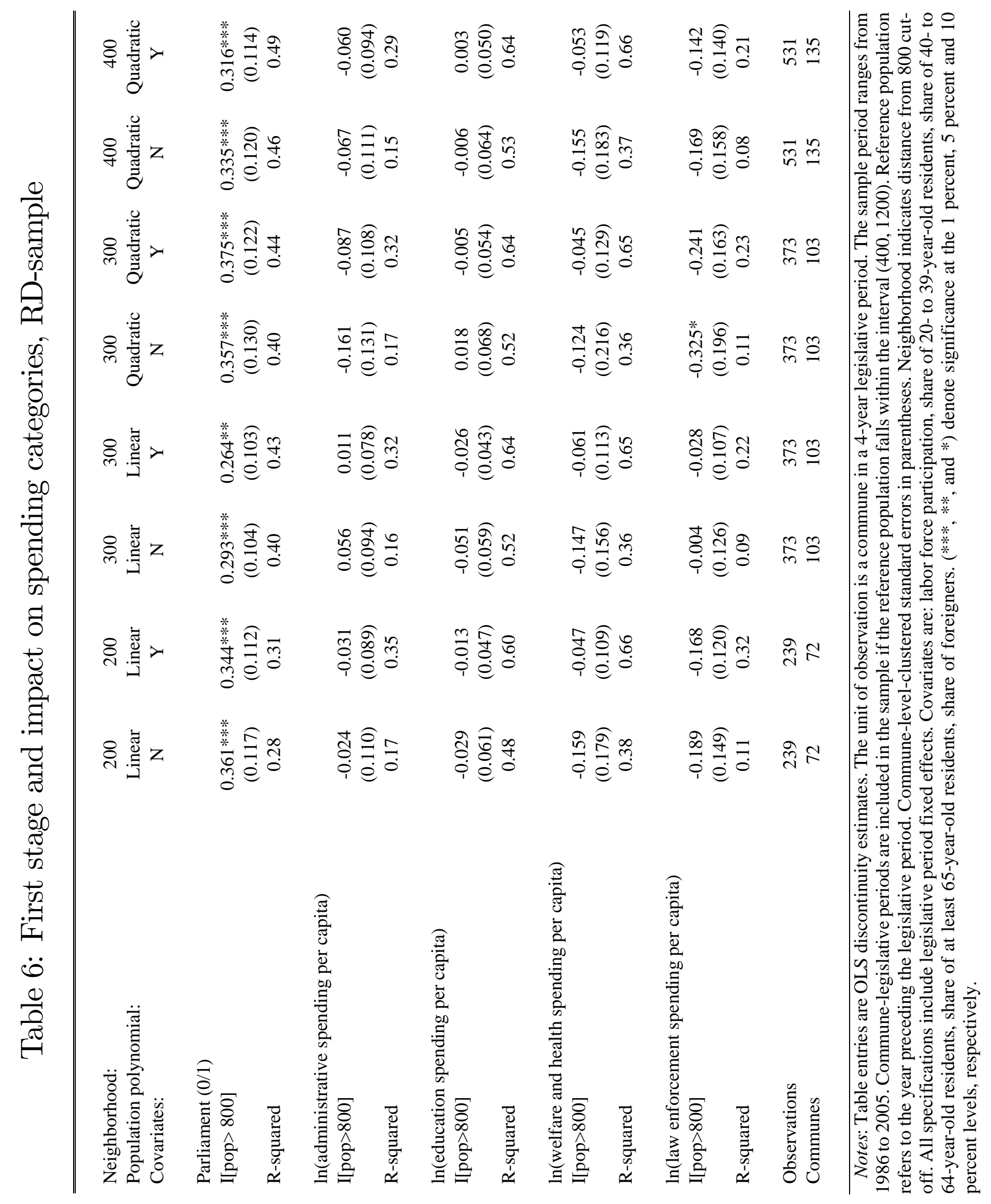




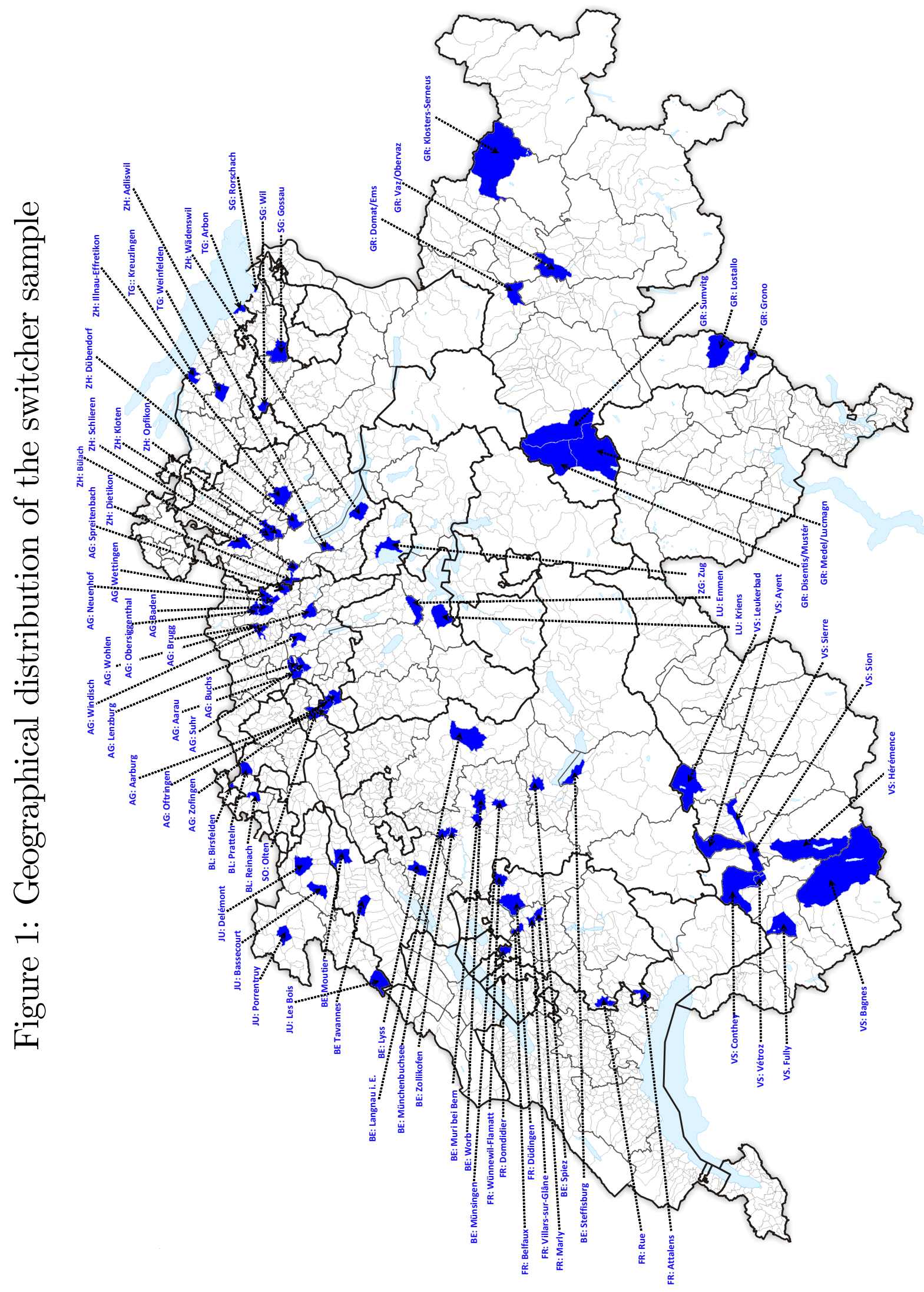



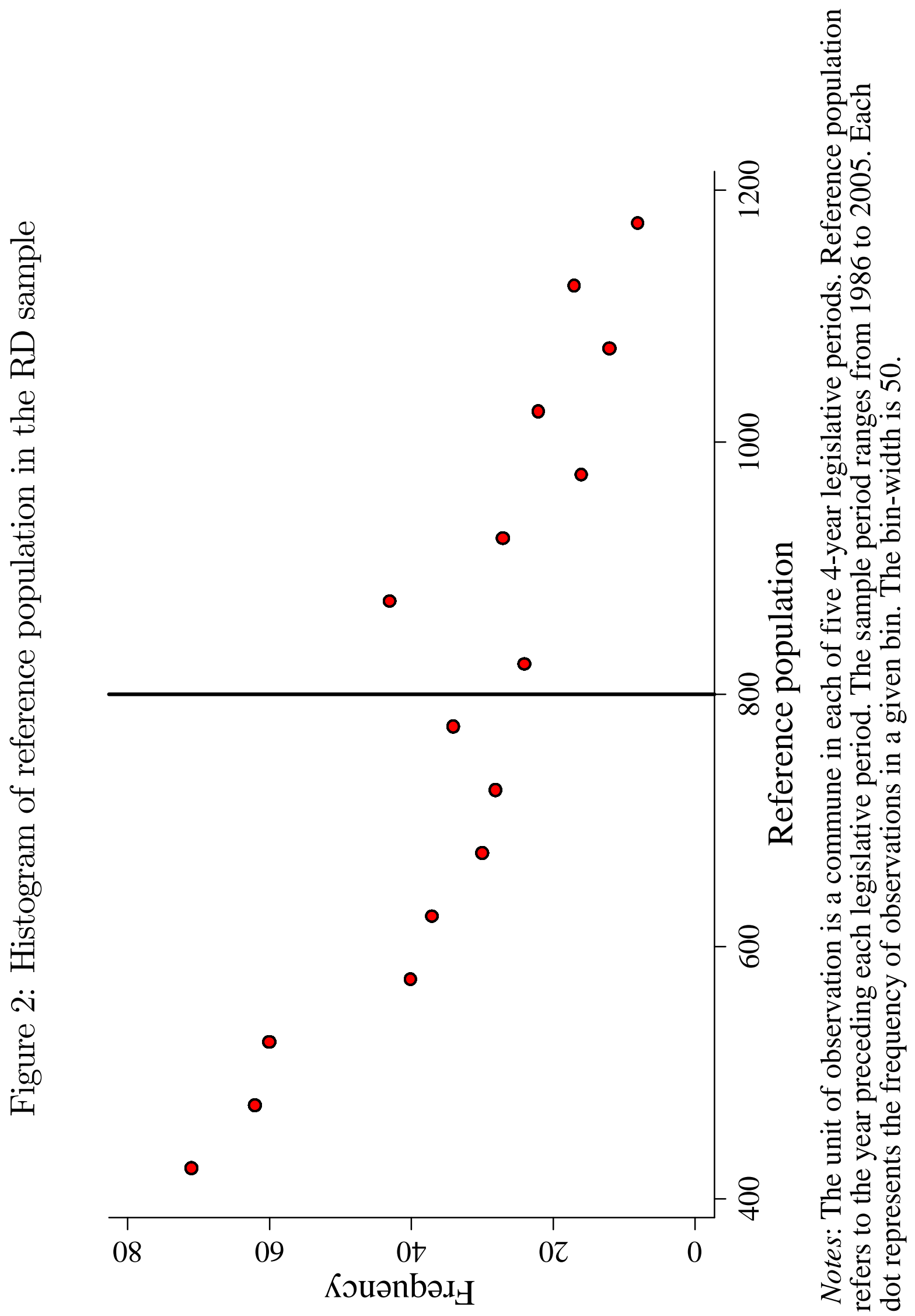


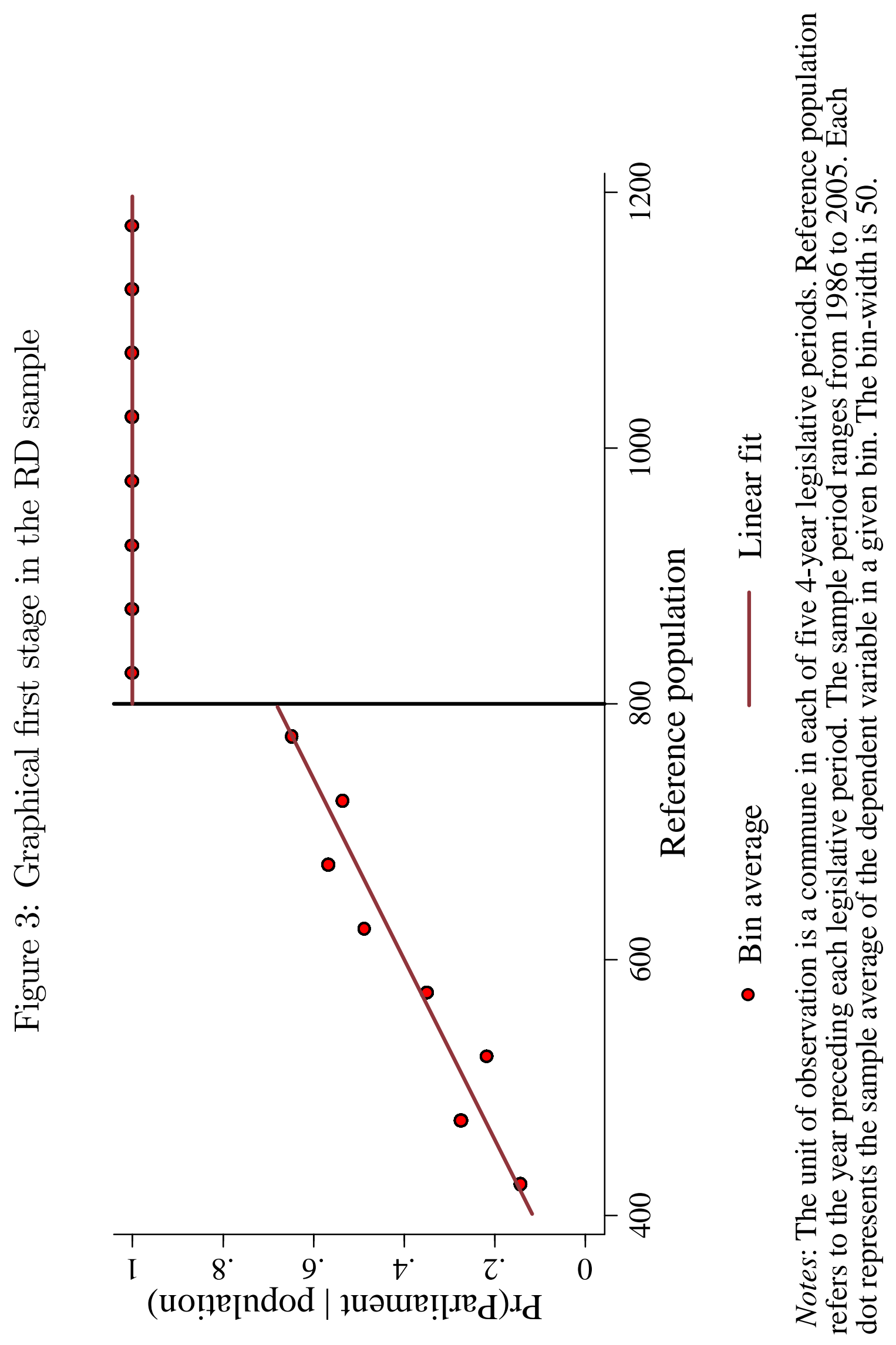




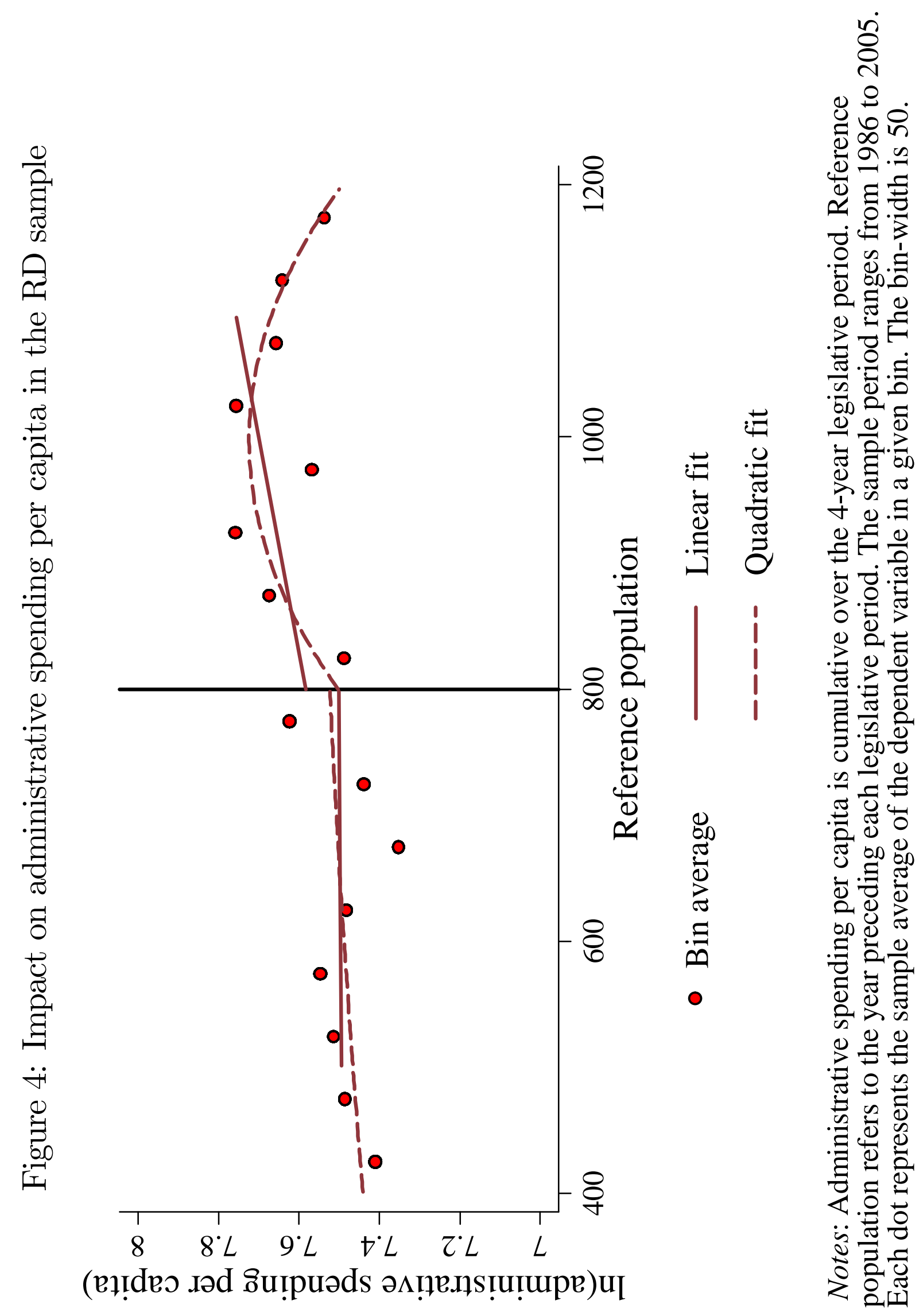




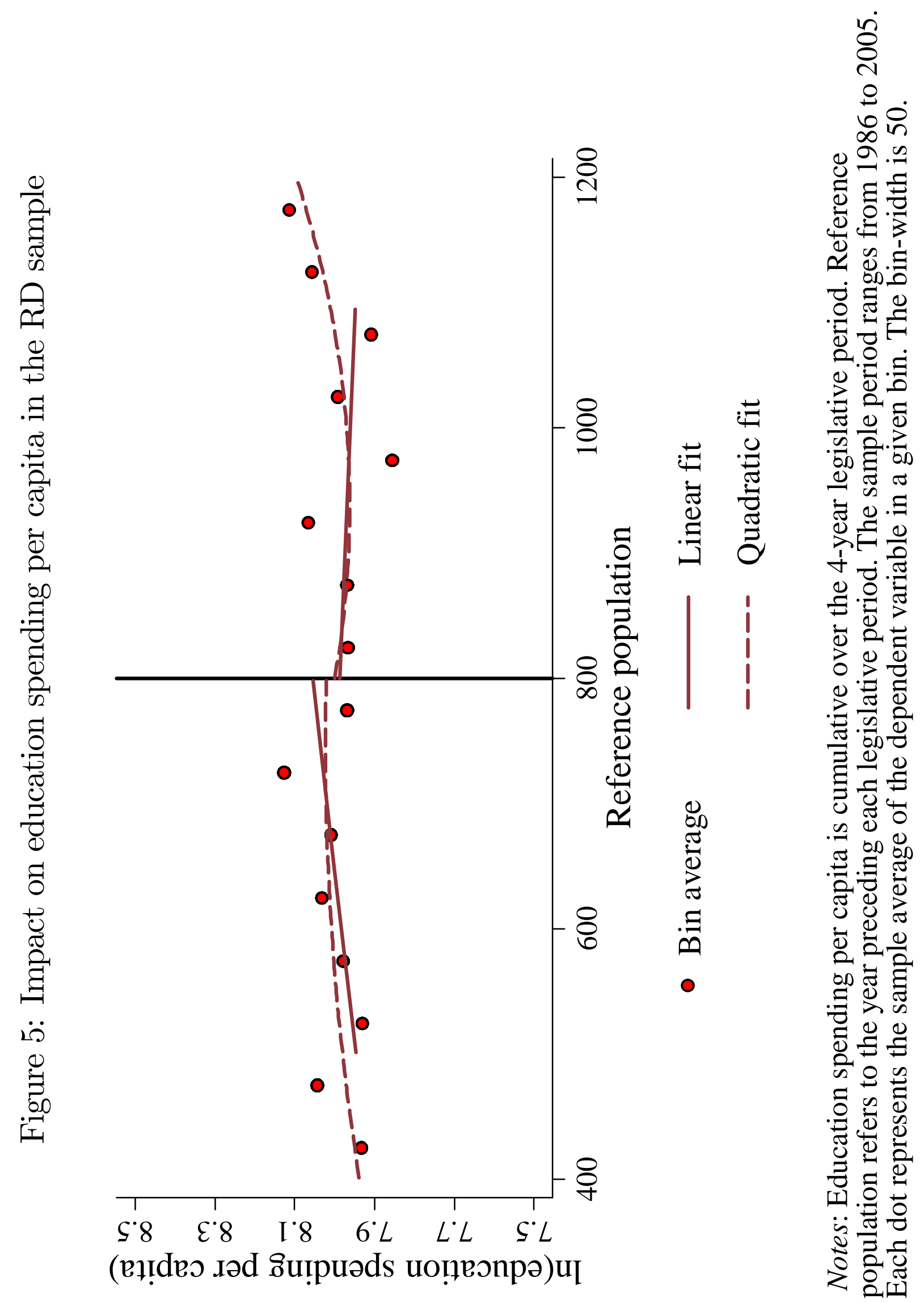



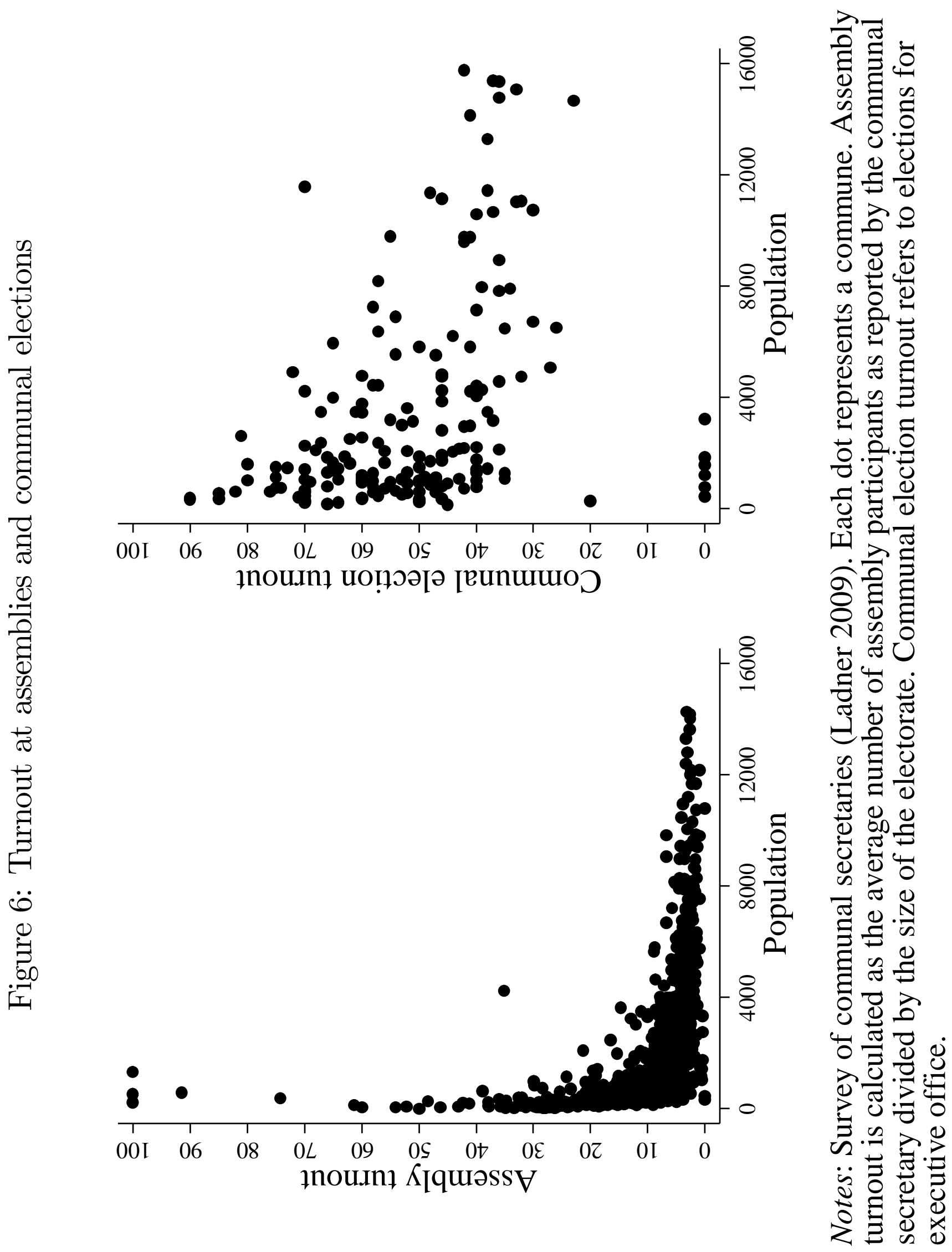
Figure 7: Age of assembly participants, the electorate and voters

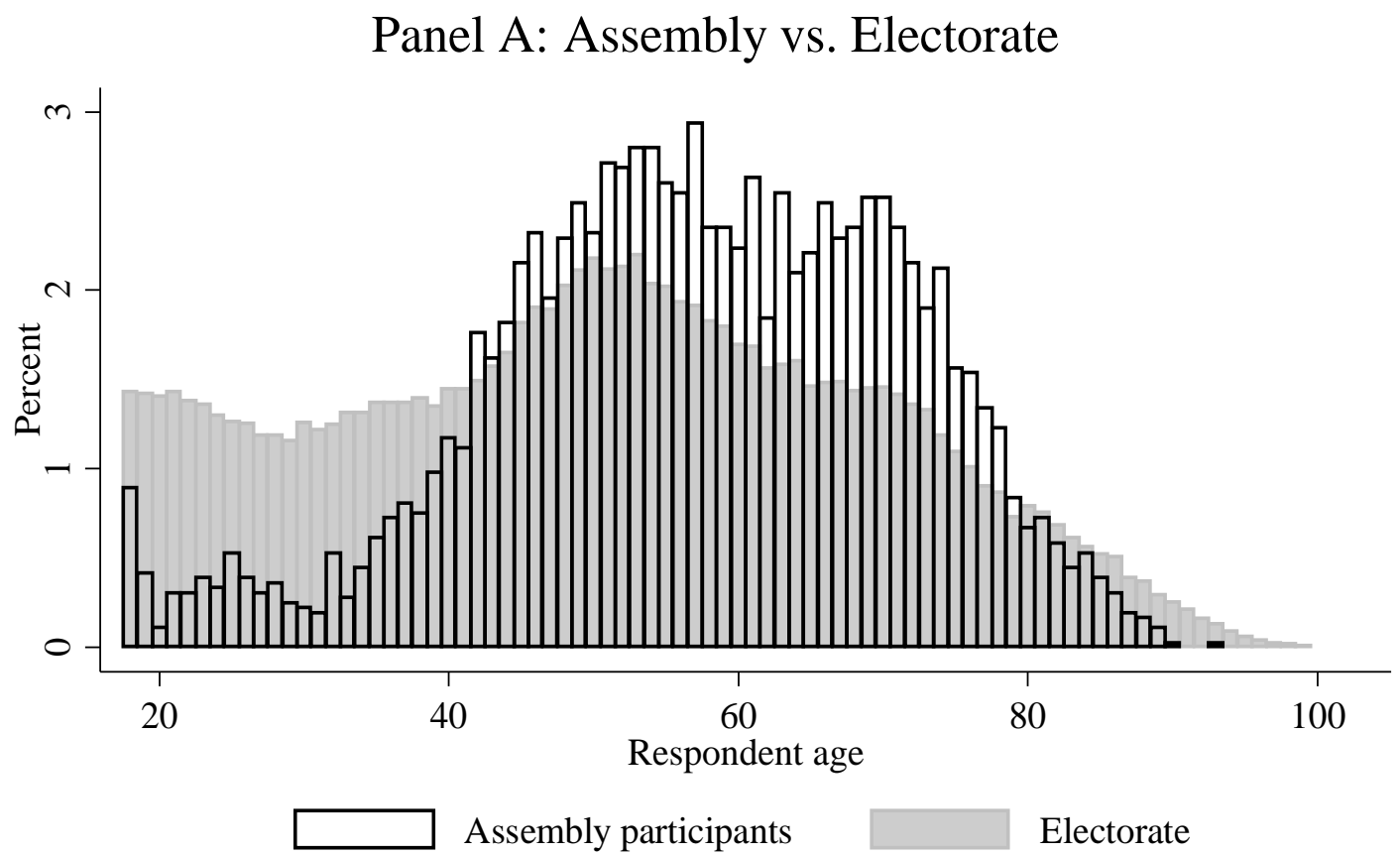

Notes: All respondents are from canton Zürich communes that took part in our 2016 assembly survey. Assembly participants responded to our survey. The electorate corresponds to Swiss citizens and is based on register data collected by the statistical office of canton Zürich.

\section{Panel B: Assembly vs. Voters in Elections}
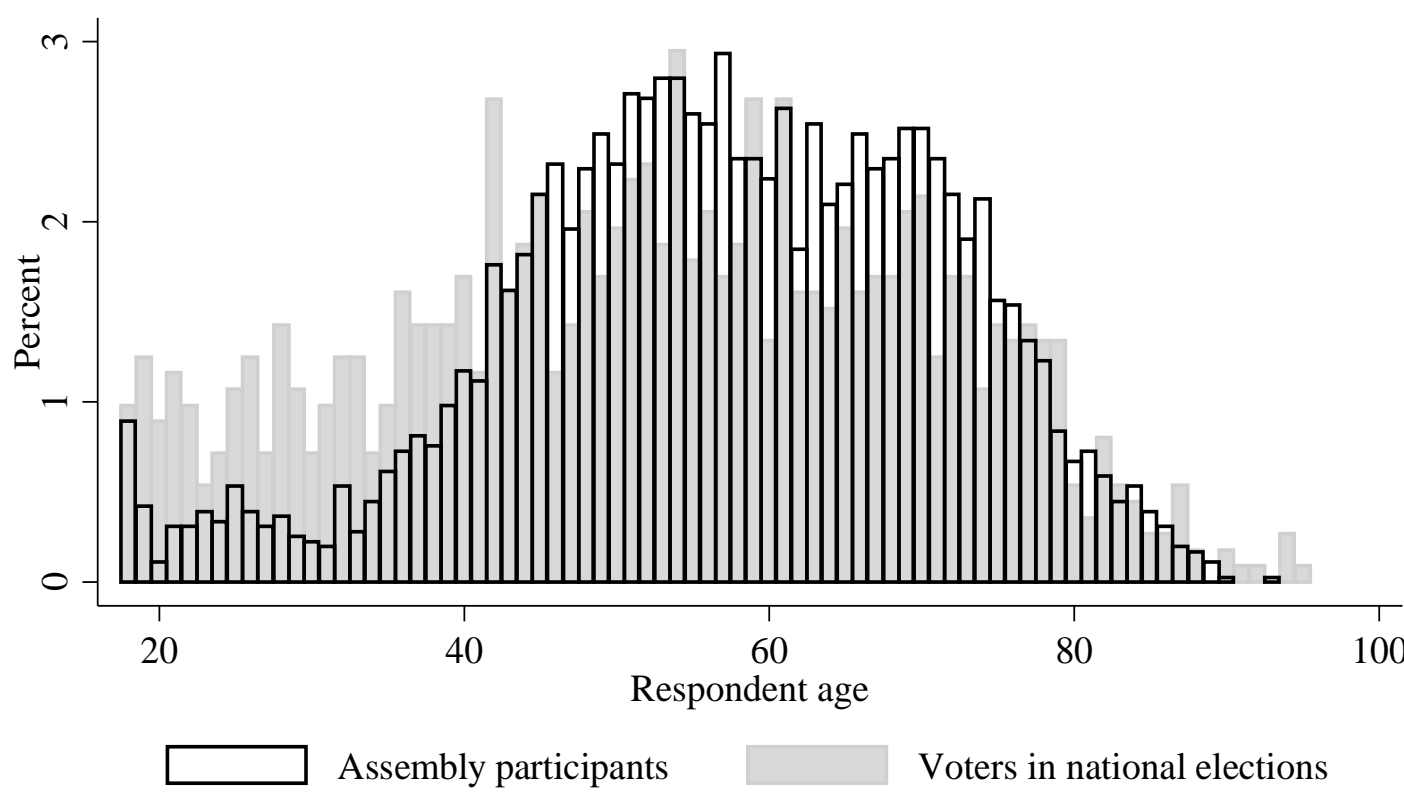

Notes: All respondents are from canton Zürich. Assembly participants are from those communes that took part in our 2016 assembly survey. Voters in national elections participated in the Swiss Electoral Studies surveys of 2011 or 2015 and are from the entire canton. 
Figure 8: Gender of assembly participants, the electorate and voters

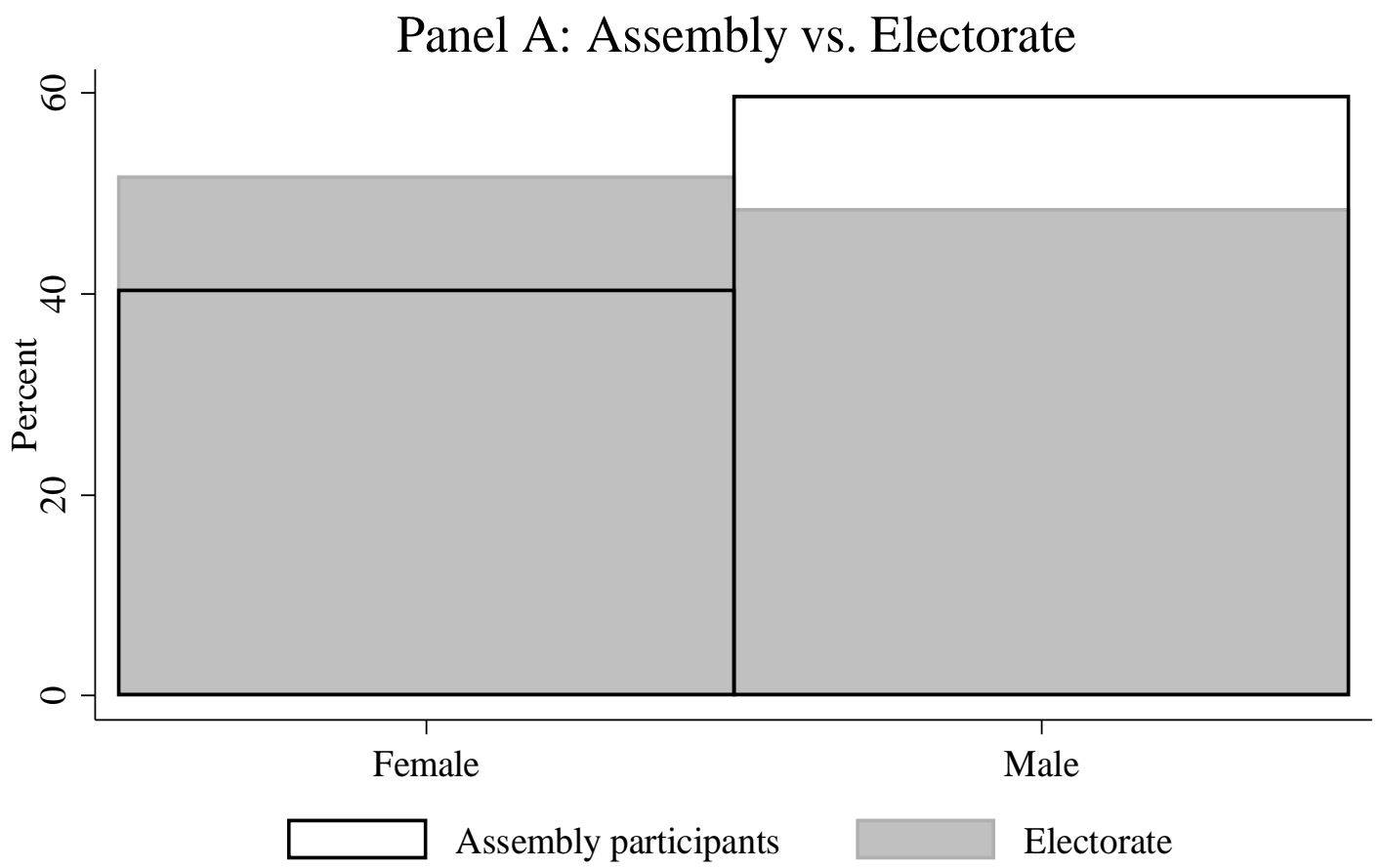

Notes: All respondents are from canton Zürich communes that took part in our 2016 assembly survey. Assembly participants responded to our survey. The electorate corresponds to Swiss citizens and is based on register data collected by the statistical office of canton Zürich.

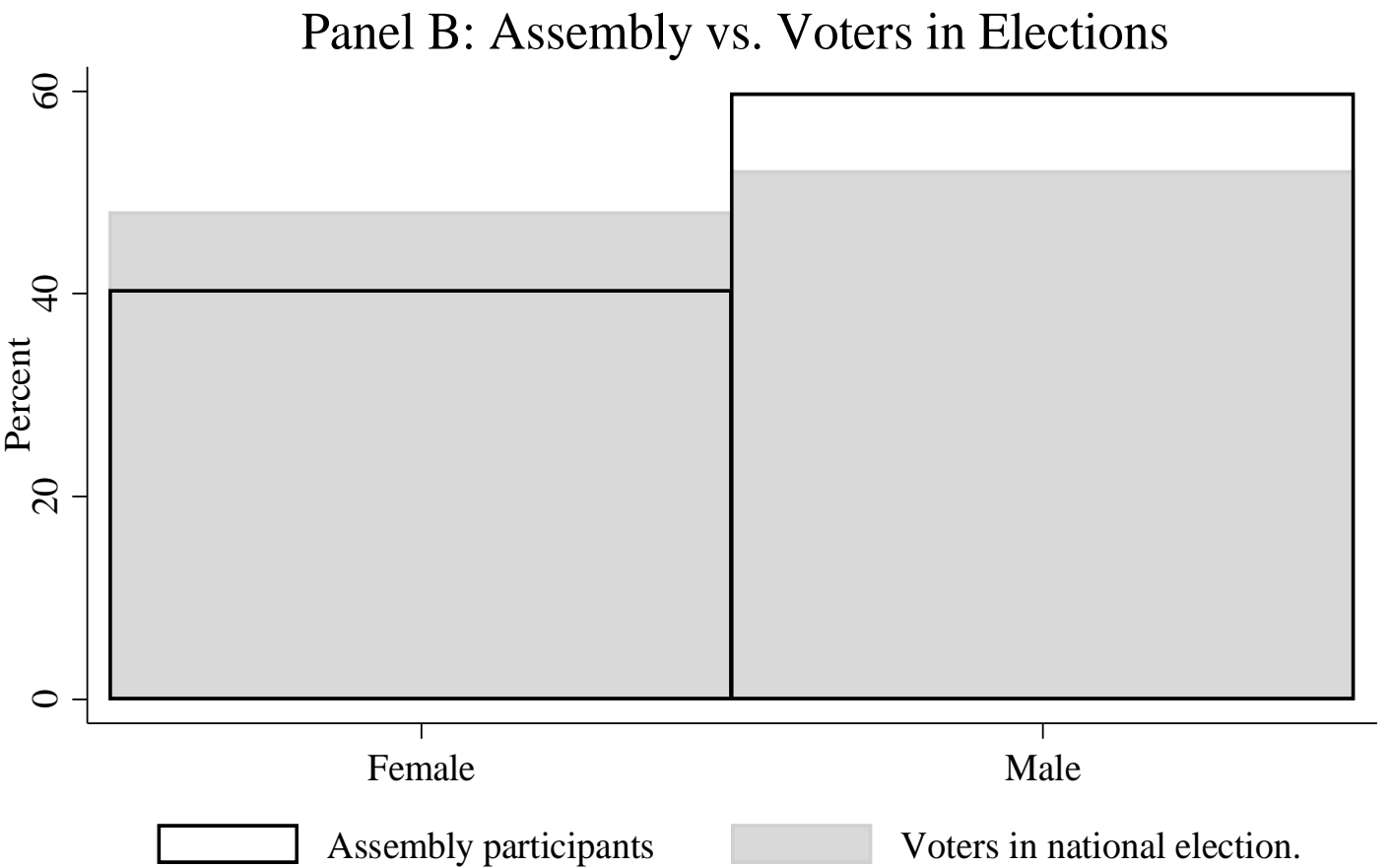

Notes: All respondents are from canton Zürich. Assembly participants are from those communes that took part in our 2016 assembly survey. Voters in national elections participated in the Swiss Electoral Studies surveys of 2011 or 2015 and are from the entire canton. 